\title{
WHAT ARE IDEAS MADE OF? ON THE SOCIO-MATERIALITY OF CREATIVE PROCESSES
}

\author{
Seweryn RUDNICKI iD* \\ AGH University of Science and Technology, Faculty of Humanities, \\ Department of Society and Technology Studies, ul. Gramatyka 8a, 30-071, Kraków, Poland
}

Received 29 July 2020; accepted 21 February 2021

\begin{abstract}
This article explores the possibility that ideas are dynamic, socio-material and relational entities that come into existence with the help of materials and technologies. It starts from arguing that the popular understanding of ideas as immaterial entities (thoughts, concepts, insights) that we process mentally, communicate (symbolically) to others, and eventually realise is rooted in essentialist and representationalist philosophy and as such is not universal. It is then argued that an alternative understanding of what an idea is may be proposed within the relationist perspective that focuses our attention primarily on change and historicity. The article employs the concept of translation - borrowed from the actor-network theory - to propose that an idea is enacted slightly differently in every social situation and with the use of different materials and technologies. Importantly, the presented relational and socio-material interpretation emphasizes that it is not the "essence" of an idea but the translations it is subjected to that enable or constrain action possibilities and determine its evolution. Finally, it is proposed that following translations of ideas empirically may be a promising avenue for further research.
\end{abstract}

Keywords: actor-network theory, creativity, idea, idea generation, ideation, representationalism, translation.

\section{Introduction}

Behind the crowds, standing in front of Rembrandt's The Night Watch (1642) at the Rijksmuseum (Amsterdam, Netherlands), there is a small stand displaying Rembrandt's drawings of the spear that is depicted in the center of the picture as if it were sticking out from the painting towards the viewer. The sketches reveal how Rembrandt had experimented with different positions of the spear before finding the final one - a document of work on a small detail that proves the painter's craft and adds extra-dramaturgy to the painting. Yet, what the sketches also show is the process of arriving at a certain idea. Apparently, Rembrandt had not known how to position the spear before he made the sketches, so he came to this idea through a process of experimentation. As it involved drawing materials, time, and the

\footnotetext{
${ }^{\star}$ Corresponding author. E-mail: sewrud@agh.edu.pl
} 
actual activity of drawing, the efforts were not merely conceptual. The final idea emerged as a result of the joint efforts of Rembrandt's mind and his hands and was enabled by the drawing materials that he used.

What are ideas? What are they made of? The popular understanding assumes that ideas are conceptual entities that "appear" in a person's mind and may then be "revealed" to other people and "realized" through certain actions. However, are ideas really purely mental objects? Are they only given form when they are communicated to others or put into practice? This paper explores another possibility - that ideas are relational beings that are dependent on context and that change slightly every time they are enacted. Furthermore, materials, objects and tools - all of which are seemingly external to ideas - play a great role in how they come into being.

This article starts from distinguishing between two concepts: representation and translation. The former interprets ideas as conceptual entities with boundaries and a clearly defined essence. The latter assumes that ideas are relational, multiple, and emerge with the help of material resources and technologies. The article then goes on to show how different material aspects of ideas enable or constrain their usage and the way they function in society. Finally, the practical consequences of the proposed understanding of ideas are presented - in particular, how they may inspire idea-generation practices.

\section{Ideas, essences and representations}

My first argument is that the popular understanding of ideas is rooted in essentialist and representationalist traditions, the perspectives of which have a long history in Western metaphysics and prevail in everyday thinking.

The concept of essentialism is that everything has an essence, i.e. a set of attributes that define what a given entity really is. This essence constitutes the true nature of a thing and provides a stable foundation for its identity, which means that if one of the attributes changes, the thing ceases to exist or becomes something else. Essentialism also assumes that things are discrete and may be differentiated from each other.

The second perspective underlying the common understanding of ideas is representationalism, which proposes that language and the world are detached and have distinct ontological statuses. The relationship between them is that of representation, which means that although there is a certain reference between the world and language, words can only stand for objects, not replace them, and operations on words are not operations on objects. The representationalist perspective is also a dualist perspective as it separates immaterial words and descriptions from the material world of objects. Interestingly, in pre-modern times, language and the world were seen as overlapping, which can still be observed today in magical thinking (e.g. a belief that curses or blessings may have a direct effect on reality).

Without aiming to present even a brief summary of the criticism of essentialist and representationalist perspectives here (see the works of Quine (1992), Popper (2005), Rorty (2011) and Mitterer (2011), for example), I would like to argue that both traditions are foundational for the way in which ideas are commonly understood. First, it is rather taken 
for granted that ideas, though not directly observable, are like material objects, i.e. they have inner essences and stable identities which can be specified (and on this basis, one idea can be distinguished from another). Second, representationalism is apparent in the common assumption that ideas are immaterial entities (thoughts, concepts, insights) that we may think of (in our minds), communicate (symbolically) to others, and put into practice (make real). In line with this perspective, ideas attain their final "shape" in the course of mental processes (ideation, idea generation) and may exist in this conceptual realm before being "implemented" or "realized", as if the processes of implementation and realization were simply limited to execution or articulation of an idea that already exists. The same perspective could be applied to the communication of ideas. It is assumed that first an idea appears and resides in someone's head, and only then is it communicated (when it takes on a symbolic form). Thus, in this view, an idea and its expressions and realizations are separated and belong to different ontological realms. Yet, what is changed between ideation and implementation is only the form of the idea, while its essence (inherent and internal) remains relatively intact (at least, when the process of implementation has been done correctly).

This understanding seems taken for granted but it has several important consequences. First, as it positions ideation as a predominantly mental process, it emphasizes its cognitive and psychological aspects. Thus, this unsurprisingly builds a "natural" connection between idea generation and such disciplines as "creative thinking" and the "psychology of creativity". This is evident from the topics covered by best-selling academic handbooks that focus on the emotional, motivational, and personality-related conditions of creativity (see for example Kaufman \& Sternberg, 2010). Treating ideation as an internal mental process also leads to disregarding the role of the body, physical objects, and the instruments that are used in its course, because if ideas are "thoughts" that appear through "thinking", objects, materials and technologies are merely tools or silent witnesses of idea-generation processes. Although they may help with the generation or communication of ideas, they are not the constitutive elements of ideas or parts from which ideas are made: they are simply vehicles in which ideas travel.

The essentialism that underpins this view also fosters certain directions of reflection on ideas. If ideas are distinct and separate entities, then it is interesting to inquire about their origins, i.e. the moment at which they appear in their final shape. This perspective can be noticed in popular narratives and histories of inventions and discoveries in which, after (a sometimes protracted) process of "incubation", an idea is "born" in a momentary flash of insight. Within this analytical framework, it is natural to consider the exact moment at which an idea emerges or to compare different ideas and try to find a connection, inspiration, or borrowing between them. It is also possible to inquire as to how ideas disperse and circulate among social environments, as if an idea were an object that can be transported from one place to another relatively intact. However, what this approach obscures is, for example, the exploration of the emergence and evolution of half-ready ideas, the interactions that exist between them, and the dynamic transformations that they may go through. 


\section{The relationist and anti-dualist perspective}

In spite of the widespread acceptance of the essentialist and representationalist understanding of ideas, this is not the only possible or even the most useful way of thinking. Essentialism can be contrasted with the relationist perspective, which proposes that, rather than essence, the primary aspects of reality are substance and stability, and change and historicity. According to relationists, rather than having a stable nature and identity, things are the effects of the relationships and contexts that they are embedded within. In contrast to the representationalist approach, the anti-dualist approach questions the primary character of any ontological realm and instead proposes monistic or "flat" ontologies (Bińczyk, 2007).

Moving on to more specific and operational notions that can replace the essentialist and representationalist framework in the understanding of ideas, the concept of translation may be proposed as an interesting alternative. The term translation has been popularized within the actor-network theory, primarily in studies on the production and application of scientific knowledge. As Latour (1999a) argues, knowledge is a process in which the element of the world which is studied is subsequently translated into many different objects. For example, when examining a tropical forest, scientists take samples, transport them to laboratories, turn them into preparations, subject them to laboratory testing, develop diagrams and charts showing the results, propose concepts and models, and finally write and publish scientific papers. According to Latour, this process is a chain of successive translations which simultaneously preserve the continuity of the object that is translated. However, this process also involves transformation, inconsistency and displacement (Callon, 1984; Callon \& Latour, 2015; Law, 2006). Neither the samples nor the results of the laboratory tests or scientific papers are the same thing as the forest that was researched, yet at the same time they stand for the forest; such simultaneous aspects of continuity and displacement are specific to translation. From this perspective, however, there is no essence, no integral that becomes represented in language in a single, dichotomizing move - only a chain of successive translations.

Another important aspect of the concept of translation is that it diminishes the value of the epistemological question of how reality is represented in language. This problem is fundamental for representationalism and is often dealt with by arguing that reality becomes distorted (in one form or the other) in its symbolic representations. Instead, the notion of translation shifts our interest to some ontological questions: How do translations come into being? How are they realized? What are they made of? The answer usually points to the role of the objects, materialities, and technologies that help to make translations. It is argued that laboratory tests, charts and scientific texts are only possible if a set of heterogeneous tools, objects and materials is employed. Moreover, translations often involve ontological "shifts". In the example proposed by Latour, samples of soil are turned into numbers and charts by laboratory devices, which are then turned into a print-and-paper article in a scientific journal. Importantly, these transformations entail not only meaning but also changes to the level of the substance from which the objects are made.

The ontological aspects of translation processes are well-illustrated in Mol's (2002) study of atherosclerosis. In this work, the central question is how the illness and the patients' bodies are translated in the course of social and medical practices. Mol shows how the body is 
talked about in an outpatient clinic, represented in numbers after angiography, cut in surgical rooms, and examined with a doctor's hands or through the lens of a microscope. These practices do not just represent the body but actively and directly translate it into different objects and materials. In these processes, the body is "enacted" and "done" with the help of instruments, numbers, concepts, hands and minds. From this perspective, the body ceases to be something stable (as, according to the essentialist, it is) or is reduced to its symbolic representation (as it would be in the representationalist perspective), but it becomes a multiple being that is enacted in many different forms and contexts.

The third, final, and possibly the most important aspect of translation is its primordial feature, which is that it enables action. In other words, translations are definitely not just transformations of symbolic meaning (as is perhaps somewhat confusingly suggested by the linguistic connotation of the term), but rather processes that result in the appearance of new action possibilities. In the examples given above, the results of the translations of the tropical forest allow actions, such as the forest being transported into laboratories and being further examined by using samples of soil and laboratory preparations. Within a hospital environment, translation of the body allows different forms of examination, diagnosis, therapy and care. In other works, Latour $(1983,1999 b)$ also shows how compasses, sextants and maps helped empires to visualize lands and exert power over conquered territory. In all these instances, translations lead to new possibilities for action and new results. In this way, the notion of translation moves our interest from the representation of reality in language to examining the forms of action it enables.

\section{Ideas and translations}

How can relational understanding and the notion of translation be applied to ideas? First, it helps to redefine our understanding of what an idea is. From this perspective, an idea is not a concept or a mental entity that is expressed in a certain form: it is something that appears in the course of a certain practice and is never entirely isolated from it.

Let us consider an example. In the process of adding an extra function to improve a digital product, this idea will change from its first formulation to something slightly different because it is discussed between employees of a research and development department, written down in post-meeting memos, shared with other employees during informal discussions, presented to executives, prototyped and tested with end-users, and implemented to produce the final product. Although there certainly is a continuation between all these enactments of the idea, there are also differences, displacements, shifts and transformations. In this case, we can regard these processes as translations of an idea.

What kind of translations are these? On one level they are just modifications of the cognitive "content" of an idea: some of its aspects may be stressed, added or elaborated, while others are omitted or diminished, depending on the situation and the audience. They also relate to the social norms that regulate what can be done with an idea in a given social context. In some contexts (like brainstorming sessions), it is appropriate to modify an idea (even wildly), add or take away some elements, or propose alternative ideas (actually, the more the better, as creativity facilitators would tell us); in other situations ideas are treated as valuable 
objects, protected against competition or modification, and defended against criticism. In this way, the social aspects of the situation influence the way in which an idea is translated.

However, it should also be taken into account that an idea becomes ontologically altered (in terms of substance) when it is discussed, written down, sketched, coded and implemented. In every such enactment of an idea, a wide array of elements is employed and all the words, drawings, schemes, notes, descriptions, models, presentations, explanations etc. enable its emergence. They actively constitute what an idea is in each of these contexts; they do not just help ideas to be communicated, they genuinely create them. In this sense, ideas are socio-material objects.

From this perspective, in every context in which an idea appears, it is enacted with the use of different materials and technologies and becomes something slightly different each time. Hence, contrary to the view that an idea is something that exists out there - that resides in someone's brain and is expressed in certain situations - the relational understanding allows us to focus on how an idea emerges and comes into being, and how it is translated from one situation to another. In this view, there is no starting point, no finite idea that precedes its enactments: there is only the process of constituting and re-constituting ideas through a potentially infinite series of translations.

This approach also helps us to see ideas as being multiple and dynamic rather than singular and stable objects. In fact, it is the stability and singularity of a given idea that is in need of explanation.

So, what are translations for?

\section{Actionable ideas}

Here is how Watson recalls the crucial moment when he - with the use of a metal, 3-dimentional molecular model - came to understand how pairs of bases may be connected in deoxyribonucleic acid (DNA):

"When I got to our still empty office the following morning, I quickly cleared away the papers from my desktop so that I would have a large, flat surface on which to form pairs of bases held together by hydrogen bonds [using the metal model]. Though I initially went back to my like-with-like prejudices, I saw all too well that they led nowhere [...] [I] began shifting the bases in and out of various other pairing possibilities. Suddenly I become aware that an adenine-thymine pair held together by two hydrogen bonds was identical in shape to a guanine-cytosine pair held together by at least two hydrogen bonds. All the hydrogen bonds seemed to form naturally [...] [The] answer to everything was in our hands" (1996, p. 69).

What is particularly important in this recollection is that the physical model of bases that were connected with molecular bonds was not just a representation of Watson's idea. Clearly, prior to the manual operations conducted on the model, the final idea had simply been non-existent. It was the model that allowed this final idea to emerge and be articulated.

The notion of translation gives an analytical foundation for treating objects and materials as constitutive of ideas. Rembrandt's pencil and paper enabled the emergence of the idea of how to position the spear; the mental molecules helped elicit the idea of DNA structure. Materials, instruments, technologies, diagrams, canvasses and the like have similar functions. 
Even more importantly, technologies and materials involved in the process of translations endow ideas with attributes that allow different actions to be carried out in accordance with them. In this way, they can foster or hinder action possibilities.

Let us consider the example of sticky notes - a popular tool used for group discussions, brainstorming sessions and co-creation processes. They are often described as a useful tool for ideation, especially in the design world, which is sometimes called "the world of sticky notes" (Stickdorn \& Schneider, 2010, p. 21). It is important to note how the material structure of sticky notes quite straightforwardly impacts how ideas may be generated. First, as sticky notes are often very small, it is only possible to write a few words on them. This is especially the case if wider markers are used (as they should be if we want to make our idea visible to the other people in the room, which is the intended aspect of using such notes). In effect, all ideas that appear in a brainstorming session using sticky notes have to be limited to these few words and - as not all ideas can be fully expressed in this way - the usage of sticky notes not only facilitates the emergence of ideas but also limits ideas that may emerge during such sessions. Second, using sticky notes of the same size implies that all ideas are potentially equally important. In this way, sticky notes imply an evaluation of ideas - rendering them equal (if we use same-sized notes) or highlighting certain ideas (if we use notes of different colors, sizes or shapes). Third, as sticky notes may be easily moved around, this also allows ideas to move in space, thus connecting or disconnecting them. Fourth, as the glue on a note is weak or dries out while it is moved around, it can sometimes fall off the wall. As a facilitator of creative group processes, I sometimes observe how the note will be picked up by a member of the group and pinned to the wall again; also, sometimes after the note has fallen down again several times, participants will give up and the idea becomes lost, perhaps forever. In this way, unintentionally, the sticky note can help to remove ideas.

As we can see, ideas can be acted upon, processed, and utilized if they are written on sticky notes and actually become hybrid beings - "note-ideas". The same applies to other materials and technologies that are commonly regarded as silent tools of idea generation, although they may actually have a more active role. In a fundamental sense, all material and digital tools, such as notes, drawings, mind-mapping tools, white boards, charts, diagrams, mood-boards, etc., enable ideas to be worked on in various ways. On a basic level, they endow ideas with spatiality and temporality. When materialized, ideas can be captured, moved, stabilized and made durable, stored, distributed, visualized, or destroyed. They also enable a wide range of cognitive responses to ideas, in which ideas may be delineated, counted, measured, compared, evaluated, associated and dissociated, remembered and forgotten. As every translation is a combination of continuity and transformation, the technological instruments and materialities that are involved also help to elaborate, modify, simplify, and rework ideas. However, perhaps the most important consequences of the action possibilities that emerge through translation processes are those related to the ways in which ideas may function in society. When materialized or digitalized, ideas become susceptible to being transferred between different social environments, where people may engage with them, discuss them, take over or oppose them. In general, ideas will be used and actions will be taken as a result of the translation process they were subjected to. 
All these action possibilities are enabled by the use of different materials and technologies. Thus, they not only serve as facilitators of the emergence of ideas, but they constitute them and endow them with action possibilities that are vital for their social existence.

\section{Make translations}

Understanding ideas as socio-material is not just a theoretical reformulation, but it also has practical consequences. This may be illustrated by the famous story of fighting cholera outbreaks in 19th century London (United Kingdom). Before the 1850s, it was believed that cholera was an airborne disease. A major breakthrough occurred as the result of a new outbreak of cholera in Soho, London in 1854, when Dr. John Snow managed to mark each individual death on a map of the district. They all turned out to be clustered around a water pump in Broad Street (London). Snow also investigated nearby areas that had fewer deaths and found that they used their own water pumps. The visualization that he made helped him to form the idea that cholera was a waterborne disease. It also helped him to introduce new public regulations for dealing with cholera outbreaks (such as only using boiled water) and London has not had a cholera epidemic since (Johnson, 2006).

Though Snow's map was not actually a translation of an idea of how to solve the cholera problem, but rather a translation (visualization) of the epidemic itself, it definitely helped new ideas to appear. The power of translations is highlighted in the analysis of laboratory practices that are described by ethnographers of science as places in which manifold translatory practices are conducted. When a "real-life" disease becomes translated into samples containing microbes, it may be transported into a laboratory and then become the subject of a number of processes: microbes may be cultivated and submitted to trials, their growth may be accelerated or slowed down, and their behavior and abilities may become the subject of intervention (Latour, 1983). Importantly, the essence of such practices has little to do with formal knowledge and scientific reasoning. Rather, they are ways in which new processes become possible and new knowledge is accumulated.

In both popular and even expert opinions, objects, materials and technologies are means by which the creativity of individuals and groups may be improved (just like writing ideas on sticky notes fosters the mutual inspiration of creativity group members, or putting people in stimulating rooms enhances the possibilities for "out-of-the-box" thinking). Yet, although it acknowledges the facilitatory role of materials and technologies, this approach still focuses on the cognitive aspects of ideation processes: ideas remain mental objects and ideation is still a predominantly conceptual activity. The relational understanding of ideas proposed in this article suggests a different approach: ideation may be performed by multiple translations of ideas with the use of different materials and devices. Just as in the abovementioned laboratory practices that involve manipulation of the material that is being researched, ideation could be improved just by producing different materializations and enactments of ideas that would offer new action possibilities and result in further modifications and improvements.

To some extent, this approach has been applied in the way prototypes are used in design practices (van Boeijen \& Daalhuizen, 2010; T. Kelley \& D. Kelley, 2013). Instead of being treated as as-close-as-possible approximations of the final solution or just presentations of ideas, they are often treated as objects that primarily allow interaction and experimentation 
with ideas. In this approach, prototypes are initially prepared with minimum effort and using cheap materials; these might be physical prototypes, videos, storyboards or role-playing, but in any case they are done quickly and cheaply. The sense of this strategy is to allow ideas to be translated into prototypes that are visible and tangible. When prototyped, ideas may be seen, discussed, explored, transported and shown to other people (teams, executives, end-users, etc.). Importantly, prototypes allow people to interact with ideas; they inspire engagement and action and bridge the gap between thinking and doing.

\section{Conclusions: follow translations}

Instead of treating ideas as stable objects with clearly defined boundaries, this article proposes that they be interpreted as relational beings that are slightly different each time they are enacted. The article also emphasizes the role of materials and technologies, arguing that they are not just the means to make ideation processes easier, but that they actually help to constitute ideas and endow them with different action possibilities. Focusing on translations of ideas also offers a different outlook on how ideation processes may be made more successful.

Yet, to explore this way of understanding fully it seems necessary to follow translations of ideas empirically. Just like Mol tracked translations of the body in clinical practices, following them from outpatient clinics to surgical rooms and laboratories, the analogical tracking of concrete ideas is a promising option for further studies. Although difficult, seeing precisely how an idea is modified across different social settings, how the translations of that idea happen, what they involve, and what the end result is could be a promising avenue for further studies on ideas.

\section{Acknowledgements}

I express my gratitude to Guido Enthoven, Rico Sneller, Jos Kessels, and other contributors to the Science of Ideas initiative for their helpful comments on my idea for this paper and its earlier versions. All remaining shortcomings are my own.

\section{Funding}

The research related to this article were financially supported by AGH University of Science and Technology, Faculty of Humanities, Kraków, Poland.

\section{References}

Bińczyk, E. (2007). Obraz, który nas zniewala: wspótczesne ujęcia języka wobec esencjalizmu i problemu referencji. Seria: Horyzonty nowoczesności. Universitas.

Boeijen, van A., \& Daalhuizen, J. (Eds.). (2010). Delft design guide: design strategies and methods. BIS Publishers.

Callon, M. (1984). Some elements of a sociology of translation: domestication of the scallops and the fishermen of St Brieuc Bay. The Sociological Review, 32(S1), 196-233.

https://doi.org/10.1111/j.1467-954X.1984.tb00113.x 
Callon, M., \& Latour, B. (2015). Unscrewing the Big Leviathan: how actors macro-structure reality and how sociologists help them to do so. In K. Knorr-Cetina \& A. V. Cicourel (Eds.), Advances in social theory and methodology: toward an integration of micro- and macro-sociologies (pp. 277-303). Series: Routledge Library Editions: Social Theory. Routledge.

Johnson, S. (2006). The ghost map: the story of London's most terrifying epidemic - and how it changed science, cities, and the modern world. Penguin Books Ltd.

Kaufman, J. C., \& Sternberg, R. J. (Eds.). (2010). The Cambridge handbook of creativity. Cambridge University Press. https://doi.org/10.1017/CBO9780511763205

Kelley, T., \& Kelley, D. (2013). Creative confidence: unleashing the creative potential within us all. Crown Business.

Latour, B. (1983). Give me a laboratory and i will move the world. In K. D. Knorr-Cetina \& M. Mulkay (Eds.), Science observed: perspectives on the social study of science (pp. 141-170). SAGE Publications.

Latour, B. (1999a). Pandora's hope: essays on the reality of science studies. Harvard University Press.

Latour, B. (1999b). Science in action: how to follow scientists and engineers through society. Harvard University Press.

Law, J. (2006). Traduction / Trahison: Notes on ANT. Convergencia: Revisita de Ciencias Sociales, 42, $47-72$.

Mitterer, J. (2011). Jenseits der Philosophie: wider das dualistlische Erkenntnisprinzip. Passagen Verlag.

Mol, A. (2002). The body multiple: ontology in medical practice. Duke University Press. https://doi.org/10.1215/9780822384151

Popper, K. R. (2005). Open society and its enemies. Vol. 1: The Spell of Plato. Routledge. https://doi.org/10.4324/9780203995167

Quine, W. V. (1992). Pursuit of truth. Harvard University Press.

Rorty, R. (2011). Objectivity, relativism, and truth. Series: Philosophical Papers. Cambridge University Press.

Stickdorn, M., \& Schneider, J. (2010). This is service design thinking: basics - tools - cases. BIS Publishers.

Watson, J. D. (1996). The Double Helix: a personal account of the discovery of the structure of DNA. Scribner Classics. 